\title{
When postpublication peer review stings
}

$\mathrm{O}$ pinions about whether a critique of research is legitimate comment or personal attack can vary between those doing the critiquing and those receiving it. In scientific publishing, authors usually don't see peer reviewers' criticisms. But in the growing community of postpublication peer review - carried out on blogs, social media, comments sections and online venues such as PubPeer - criticism of published research is done in the open.

Though it can lead to heated debates and accusations of mean-spiritedness or even bullying, challenging research findings online is a positive evolution for science, says Raphaël Lévy, a professor of biochemistry at the University of Liverpool in the United Kingdom.

"It provides an opportunity to bring more scrutiny and more debate into science, and that is a good thing," says Lévy.

It is inevitable that mistakes will occasionally slip through in the traditional peer-review process, considering there are typically only two or three people reviewing the research for a limited period of time. Continuing the evaluation of published work online by the scientific community is necessary, good for science and will likely be de rigueur for future generations of researchers, says Philip Moriarty, a physics professor at the University of Nottingham in the UK.

"When you publish, that should be the start of the process, not the end of the process, in terms of debate," says Moriarty.

Both Lévy and Moriarty have themselves written lengthy and frequent criticisms about the quality of research on a rather specific topic: whether molecules spontaneously assemble themselves into discrete stripes around gold nanoparticles. This has become known as the "stripy nanoparticles" controversy.

According to the researcher behind the work - Francesco Stellacci, head of the Supramolecular Nanomaterials and Interfaces Laboratory at the École polytechnique fédérale de Lausanne in Switzerland - the online debate became personal and nasty.

In a draft of an open letter sent to $C M A J$, Stellacci writes that he has been

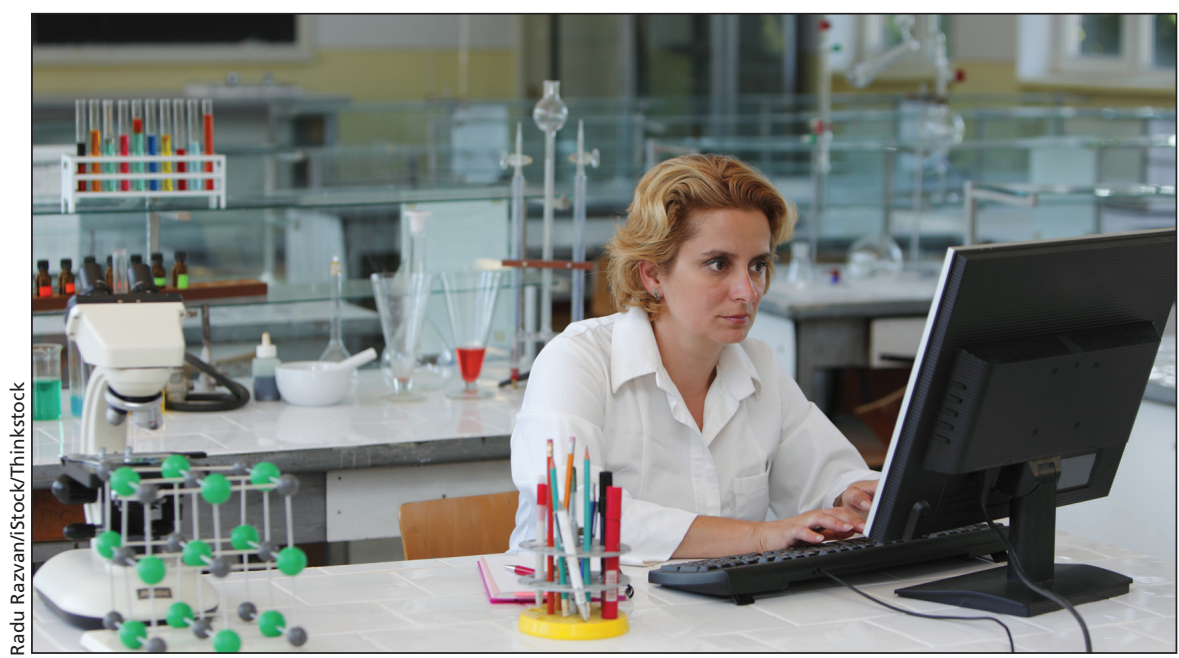

Online scrutiny of published research can foster scientific debate but may damage researchers' reputations.

the subject of a "long cyber-bullying campaign." He says he has been mocked online and accused of misconduct and data fabrication.

"I have endured more than a year of mocking over results that are reproducible in multiple laboratories and have been found to be convincing by leading experts," the letter states. "All of this while my papers were going through peer review and my own students were suffering in their personal and professional life because of unfounded, unprofessional, and probably unethical behaviors."

Stellacci says he is not opposed to open debate on his work or postpublication peer review, as long as it is conducted in an appropriate way. "There needs to be more of an ethical code of what we do in scientific debates," he says. "In my case, if I look at the debate, some decent arguments were made against me, but also some wayout-there things."

According to Lévy, however, the criticisms of Stellacci's work do not enter the realm of bullying. As long as those involved stick to the facts, an online discussion about science, no matter how heated, is within bounds.

"The reason this can be difficult is because, sometimes, people define themselves by their work, so if you attack their work, they feel personally attacked, but that is not a good reason not to attack the work," says Lévy. "If there are prob- lems with the body of work, it needs to be discussed."

Moriarty agrees, suggesting that although it may sting to have your body of work criticized in the open, that doesn't mean the process is malicious. Restraint should be shown, though, in how one expresses their objections to another's research, he acknowledges. "I must admit, there were times I could have chosen my language with a little more care," says Moriarty.

Still, no matter how carefully chosen the words, the inputs versus outputs of postpublication peer review remain totally skewed, says Frank Gannon, director and CEO of the QIMR Berghofer Medical Research Institute in Herston, Australia. Online accusations, justified or not, can do incredible damage to a researcher's reputation.

Traditionally, people with objections to research write letters to the journal in which it's published, and the original author is given a chance to respond. Though this can be cumbersome and takes time, it at least allows a third party — the journal's editors - to referee the debate.

"To bypass that and not have a third party look carefully at what is happening can lead to fairly rough justice," says Gannon. "A person's career can be ruined without any judge or jury." Roger Collier, CMAJ

CMAJ 2014. DOI:10.1503/cmaj.109-4817 